\title{
EFEITO DA ASSOCIAÇÃO DE FARINHA DE POLPA DE BANANA VERDE E INULINA NA MULTIPLICAÇÃO DE STREPTOCOCCUS THERMOPHILUS EM LEITE FERMENTADO
}

\begin{abstract}
Association effect of green banana pulp flour and inulin on the multiplication of Streptococcus thermophilus in fermented milk
\end{abstract}

\begin{abstract}
Caroline Azevedo Moreira ${ }^{I}$, Paulo Sérgio Monteiro ${ }^{I *}$, Pablo Henrique Soares dos Santos ${ }^{I}$, Letícia Campos Gois $^{I}$, Milene Therezinha das Dores ${ }^{I}$
\end{abstract}

\section{RESUMO}

Os leites fermentados e os prebióticos são considerados alimentos funcionais e têm despertado cada vez mais o interesse das indústrias. Este estudo objetivou avaliar a influência da farinha de polpa de banana verde (FPBV) e inulina na multiplicação de Streptococcus thermophilus durante o processo fermentativo e por um período de 28 dias de armazenamento do leite fermentado. Os ensaios foram realizados em três tratamentos com três repetições, sendo a formulação A constituída de leite sem adição de FPBV e inulina, a formulação B contendo leite e FPBV e a formulação C contendo leite, FPBV e inulina. A FPBV apresentou 14,25\% de umidade, $4,01 \%$ de cinzas, $2,28 \%$ de proteínas e $1,38 \%$ de extrato etéreo. Os valores de $\mathrm{pH}$ inicial das formulações A, B e C foram 7,30, 7,14 e 7,15, respectivamente, e após 4 horas atingiram os valores 4,57, 4,73 e 4,66, respectivamente. Os valores de acidez titulável inicial das formulações A, B e C foram $0,15 \%, 0,16 \%$ e $0,14 \%$, respectivamente. No final do processo, a acidez atingiu os valores $0,93 \%, 0,98 \%$ e $0,86 \%$, respectivamente. As contagens de $S$. thermophilus das formulações A, B e C não apresentaram diferença significativa nos tempos de 1, 14 e 28 dias e as contagens médias foram, respectivamente, 9,04, 9,20 e 8,77 log UFC/g. Desta forma, a utilização de FPBV e inulina não influenciou no processo de produção de leite fermentado inoculado com Streptococcus thermophilus e na multiplicação do micro-organismo durante o armazenamento do produto.

Palavras-chave: alimento funcional; leite fermentado; prebiótico.

1 Universidade Federal de Viçosa, Instituto de Ciências Agrárias, Rodovia MG230, km 7, 38810-000, Rio Paranaíba, MG, Brasil. E-mail:psmonteiro@ufv.br

* Autor para correspondência

Recebido / Received: 25/03/2020

Aprovado / Approved: 04/06/2020 


\begin{abstract}
Fermented milks and prebiotics are considered functional foods and have aroused the interest of the industries. The objective of this study was to evaluate the influence of green banana pulp flour (GBPF) and inulin on the multiplication of Streptococcus thermophilus during the fermentation process and for a period of 28 days of storage of fermented milk. The experiments were performed in three treatments with three replications, in which formulation A consisted of milk without adding of GBPF and inulin, formulation B contained milk, and GBPF and formulation $\mathrm{C}$ contained milk, GBPF and inulin. The GBPF had $14.25 \%$ moisture, $4.01 \%$ ash, $2.28 \%$ protein and $1.38 \%$ ether extract. The initial $\mathrm{pH}$ values of formulations $\mathrm{A}$, $\mathrm{B}$ and $\mathrm{C}$ were $7.30,7.14$ and, 7.15, respectively, and after 4 hours of fermentation they reached $4.57,4.73$ and 4.66 , respectively. The initial titratable acidity values of formulations A, B and C were $0.15 \%, 0.16 \%$ and $0.14 \%$, respectively. At the end of the process, acidity reached the values of $0.93 \%, 0.98 \%$ and, $0.86 \%$, respectively. The $S$. thermophilus counts of formulations A, B and C did not present significant differences in the periods of 1,14 and 28 days and the average counts were, respectively, 9.04, 9.20 and 8.77 $\log \mathrm{CFU} / \mathrm{g}$. Thus, the use of GBPF and inulin did not influence the production process of fermented milk inoculated with $S$. thermophilus and the multiplication of the microorganism during product storage.
\end{abstract}

Keywords: functional food; fermented milk; prebiotic.

\section{INTRODUÇÃO}

Os consumidores estão cada vez mais conscientizados e preocupados com a manutenção da saúde e bem-estar, fator que tem contribuído para o aumento do consumo de produtos alimentícios com propriedades funcionais (BARAUSKAITE et al., 2018). De acordo com a Agência Nacional de Vigilância Sanitária (ANVISA), os produtos com alegação de propriedades funcionais são aqueles com capacidade comprovada de promover benefícios à saúde do consumidor (BRASIL, 1999) e entre estes, destacam-se os leites fermentados e os produtos com ingredientes prebióticos.

Os prebióticos são considerados ingredientes funcionais por não serem digeridos no trato gastrointestinal e estarem disponíveis como substratos para bactérias dos gêneros Bifidobacterium e Lactobacillus que colonizam o intestino (RAIZEL et al., 2011). As bactérias probióticas contribuem para a manutenção e melhoria da saúde do organismo, onde auxiliam na prevenção de infecções, processos inflamatórios gastrointestinais e doenças cardiovasculares (BARAT; OSCAN, 2018).

A inulina é um carboidrato de reserva considerado como prebiótico e encontrada nos vegetais, usualmente extraída da raiz da chicória (MATTILA-SANDHOLM et al., 2002). O seu consumo está relacionado a efeitos benéficos no organismo, como o aumento da biodisponibilidade de cálcio (SAAD, 2006). Na indústria de alimentos, a inulina é geralmente utilizada em substituição ao açúcar e à gordura, proporcionado redução calórica e características sensoriais desejáveis nos produtos (BORTOLOZO; QUADROS, 2007; SHOAIB et al., 2016).

$\mathrm{O}$ amido é um carboidrato de reserva de várias fontes vegetais e é considerado como a fonte mais importante de carboidratos na alimentação humana, representando $80 \%$ a $90 \%$ dos polissacarídeos das dietas. Entre as 
diversas fontes, é encontrado em abundância em grãos de cereais, leguminosas, tubérculos e frutas imaturas ou verdes. O amido é amplamente utilizado como matéria-prima na indústria alimentícia e contribui para as características de textura de grande parte dos produtos processados, onde é utilizado como espessante, estabilizador de coloides, agente gelificante e de volume, adesivo e na retenção de água (DENARDIN; SILVA, 2009). Entres os diversos produtos, é utilizado na fabricação de pães e biscoitos e também em processos fermentativos envolvendo a produção de bebidas alcoólicas e de etanol para outros fins (MORRIS; BRYCE, 2000).

$\mathrm{O}$ amido resistente é encontrado em elevada concentração na banana verde, sendo considerado o constituinte prebiótico da fruta (BATISTA et al., 2017). Assim, devido a ser uma fonte considerável de amido resistente e potássio, o uso de farinha de banana verde tem atraído a atenção dos pesquisadores. A farinha de banana verde pode apresentar acima de 50\% $(\mathrm{m} / \mathrm{m})$ de amido resistente (CAMPUZANO et al., 2018). Ao ser metabolizado pelas bactérias probióticas no intestino, o amido resistente proporciona a formação de ácidos graxos de cadeia curta, principalmente os ácidos acético, propiônico e butírico, os quais sugerem-se estar relacionados à redução de distúrbios intestinais, doenças cardiovasculares e incidência de câncer (BATISTA et al., 2017).

Assim, o processamento de banana para obtenção de farinha e amido é de interesse para a indústria de alimentos e outros fins industriais (WALISZEWSKI et al., 2003). Neste contexto, a desidratação da banana verde para produção de farinha de banana verde é uma alternativa viável para sua conservação e utilização como ingrediente funcional (MATOS et al., 2017). Para obtenção de maior teor de amido resistente, a banana verde a ser utilizada deve estar no primeiro estágio de maturação (SILVA et al., 2016).
No âmbito da indústria de alimentos, a inulina e o amido resistente estão incluídos no grupo dos principais prebióticos utilizados como ingredientes, sendo a indústria de laticínios a principal responsável pela inserção destes em produtos alimentícios (BATISTA et al., 2017). Vários estudos avaliaram o potencial de utilização da inulina, de forma isolada ou combinada, em vários grupos de alimentos, tais como leites fermentados (BORTOLOZO; QUADROS, 2007; MAESTRI et al., 2014), queijos (SANTOS et al., 2015) e produtos cárneos (VALDEZ et al., 2015). De modo semelhante, o uso de amido resistente de banana verde tem sido avaliado em diferentes alimentos como iogurte (SILVA et al., 2017a) e produtos de panificação (ANDRADE et al., 2018, OLIVEIRA et al., 2015). No entanto, não foram realizados estudos que avaliaram especificamente a utilização de inulina em associação com farinha de polpa de banana verde na fabricação de leite fermentado inoculado com Streptococcus thermophilus, o qual é reconhecido como uma importante cultura termofílica iniciadora utilizada em associação com outros micro-organismos em várias fermentações lácteas industriais.

Nesse contexto, este estudo objetivou avaliar o efeito da adição de farinha de polpa de banana verde e inulina na produção de leite fermentado inoculado com $S$. thermophilus.

\section{MATERIAL E MÉTODOS}

\section{Preparo da farinha de polpa de banana verde}

As bananas foram colhidas no primeiro estágio de maturação. Os frutos foram submetidos à lavagem com água potável, posterior sanitização com água clorada na concentração de $200 \mathrm{mg} / \mathrm{L}$ durante 15 minutos e enxágue com água potável. Na sequência, as bananas foram descascadas e a polpa foi 
cortada em pedaços de aproximadamente 1 $\mathrm{cm}$ de espessura, que foram transferidos para solução de ácido ascórbico $0,5 \%(\mathrm{~m} / \mathrm{v})$, onde permaneceram até o momento da desidratação em estufa com circulação de ar à $65^{\circ} \mathrm{C}$ durante 8 horas. Após a secagem, a polpa desidratada foi triturada em moinho de bolas e a farinha obtida foi acondicionada em embalagens plásticas à vácuo sob refrigeração.

\section{Caracterização físico-química da farinha de polpa de banana verde}

A farinha de polpa de banana verde foi submetida à análise de umidade pelo método gravimétrico em estufa à $105^{\circ} \mathrm{C}$ e análise de cinzas por meio da incineração das amostras em mufla a $550^{\circ} \mathrm{C}$ durante 6 horas. $\mathrm{O}$ teor de proteínas foi determinado pelo método de Kjeldahl, que consiste na determinação de nitrogênio total da amostra. Para conversão do teor de nitrogênio em teor de proteínas foi utilizado o fator 6,25. O teor de extrato etéreo foi obtido pela extração da fração lipídica em aparelho Soxhlet utilizando éter de petróleo como solvente. Todos os resultados foram expressos em porcentagem (AOAC, 2012).

\section{Ingredientes e cultura microbiana}

Para a elaboração do leite fermentado foram utilizados leite em pó desnatado (Molico, Nestlé, Araçatuba, Brasil), cultura liofilizada (nu-trish ${ }^{\circledR}$ ABT-4, Christian Hansen) contendo $S$. thermophilus, inulina Beneo $^{\mathrm{TM}}$ (Orafti Active Food Ingredients, Oreye, Bélgica) e banana verde (Musa sp. cv. Nanicão) proveniente do pomar experimental da Universidade Federal de Viçosa, Campus Rio Paranaíba.

\section{Processamento dos leites fermentados}

O leite fermentado foi produzido em escala laboratorial em três formulações (Tabela 1), conforme metodologia proposta por Tamime e Robson (1990), com modificações. Para cada formulação foram preparados 450 $\mathrm{mL}$ de leite, obtido a partir da reidratação de leite em pó desnatado na proporção de $13 \mathrm{~g}$ de leite em pó desnatado para $100 \mathrm{~g}$ de água destilada. A farinha de polpa de banana verde foi adicionada ao leite na proporção de $5 \%$ $(\mathrm{m} / \mathrm{v})$ e a inulina foi utilizada na proporção de $3 \%(\mathrm{~m} / \mathrm{v})$. O leite reidratado, adicionado

Tabela 1 - Formulações utilizadas para a produção dos leites fermentados

\begin{tabular}{cccc}
\hline Formulação & $\begin{array}{c}\text { Leite desnatado } \\
\text { reconstituído }(\mathbf{m L})\end{array}$ & FPBV*(g) $^{*}$ & Inulina (g) \\
\hline A & 450 & - & - \\
A & 450 & - & - \\
A & 450 & - & - \\
B & 450 & 22,5 & - \\
B & 450 & 22,5 & - \\
B & 450 & 22,5 & - \\
C & 450 & 22,5 & 13,5 \\
C & 450 & 22,5 & 13,5 \\
C & 450 & 22,5 & 13,5 \\
\hline
\end{tabular}

* FPBV: Farinha de polpa de banana verde 
ou não de farinha de polpa de banana verde e inulina, foi submetido ao tratamento térmico de $95^{\circ} \mathrm{C}$ durante 10 minutos, com posterior resfriamento à $42^{\circ} \mathrm{C}$. Em todas as formulações, o leite foi inoculado com $0,2 \%(\mathrm{~m} / \mathrm{v}) \mathrm{de}$ cultura liofilizada de $S$. thermophilus. A fermentação foi conduzida durante 4 horas na temperatura de $42^{\circ} \mathrm{C}$ e após o término, o leite fermentado foi armazenando à temperatura de $4^{\circ} \mathrm{C}$ durante 28 dias. Durante esse período, amostras das formulações desenvolvidas foram retiradas para análise microbiológica nos tempos 1,14 e 28 dias.

\section{Acidez titulável e pH do leite fermentado}

As análises de acidez titulável e pH foram realizadas em intervalos de 1 hora durante o período de 4 horas de fermentação, conforme metodologia proposta pelo Instituto Adolfo Lutz (ZENEBON et al., 2008).

\section{Análise microbiológica}

A análise de $S$. thermophilus foi realizada por meio da técnica pour plate utilizando o meio de cultura M17, conforme metodologia proposta por Silva et al. (2017b). As análises foram realizadas nos tempos de 1,14 e 28 dias de armazenamento após a fermentação. Após a inoculação, as placas foram mantidas em incubadora tipo B.O.D (Eletrolab, modelo EL 202/4, São Paulo, Brasil) a $37^{\circ} \mathrm{C}$ durante 72 horas para posterior contagem.

\section{Delineamento experimental e análise estatística}

Os tratamentos foram dispostos em delineamento inteiramente casualizado, segundo um esquema de parcelas subdivididas, em que as formulações A (leite sem adição de farinha de polpa de banana verde e inulina), B (leite com adição de farinha de polpa de banana verde) e C (leite com adição de farinha de polpa de banana verde e inulina) constituíram as parcelas e o tempo de fermentação, as subparcelas. O ensaio experimental foi realizado em três repetições e os resultados foram interpretados por meio de análise de variância (ANOVA) e análise de regressão, utilizando-se o teste $\mathrm{F}$ a $5 \%$ de probabilidade. As análises estatísticas foram realizadas utilizando-se o programa $\mathrm{R}$ versão 3.6.1.

\section{RESULTADOS E DISCUSSÃO}

\section{Caracterização físico-química da farinha de polpa de banana verde}

Os resultados das análises físicoquímicas da farinha estão apresentados na Tabela 2. A farinha de polpa de banana verde apresentou teor de umidade dentro do limite de $15 \%(\mathrm{~m} / \mathrm{m})$ estabelecido pela Resolução da Diretoria Colegiada $n^{\circ} 263$, de 22 de setembro de 2005 da ANVISA (BRASIL, 2005). Para inibir o desenvolvimento de micro-organismos deterioradores e preservar a qualidade das farinhas é importante que o teor de umidade seja de, no máximo, $15 \%$ (m/m) (FIORDA et al., 2013).

Tabela 2 - Composição química da farinha de polpa de banana verde

\begin{tabular}{lc}
\hline Variáveis & \% (base seca)* \\
\hline Umidade & $14,25 \pm 0,70$ \\
Cinzas & $4,01 \pm 0,07$ \\
Extrato etéreo & $1,38 \pm 0,16$ \\
Proteínas & $2,28 \pm 0,06$ \\
\hline
\end{tabular}

* Valores expressos por média \pm desvio padrão.

O teor de cinzas da farinha foi similar às concentrações de $2 \%(\mathrm{~m} / \mathrm{m})$ e $2,6 \%(\mathrm{~m} / \mathrm{m})$ encontradas por Torres et al. (2005) e Borges et al. (2009), respectivamente, em farinha de polpa de banana verde. Em outro estudo, Neto et al. (1998) encontraram 4,1\% (m/m) 
de cinzas na farinha obtida a partir de polpa e de casca de banana verde.

A farinha apresentou reduzido teor de extrato etéreo. No entanto, a concentração foi superior ao valor de $0,7 \%(\mathrm{~m} / \mathrm{m})$ encontrado por Borges et al. (2009), que realizaram a caracterização físico-química da farinha de polpa de banana verde para posterior aplicação em produtos de panificação, dietéticos e alimentos infantis.

A concentração de proteínas da farinha foi inferior ao teor de $4,7 \%(\mathrm{~m} / \mathrm{m})$ encontrado por Borges et al. (2009) na farinha de polpa da banana verde. Em um estudo semelhante, Neto et al. (1998) utilizaram casca e polpa da banana verde e encontraram 3,2\% $(\mathrm{m} / \mathrm{m})$ de proteínas na farinha.

As propriedades físico-químicas da farinha de banana verde podem apresentar variações e um dos fatores mais influentes é o estágio de maturação da fruta (ALKARKHI et al., 2011).

\section{Variação do pH e da acidez titulável durante a fermentação}

A Figura 1 mostra a variação do $\mathrm{pH}$ durante o processamento do leite fermentado. Os valores médios de $\mathrm{pH}$ inicial das formulações $\mathrm{A}$, B e $\mathrm{C}$ foram 7,30, 7,14 e 7,15, respectivamente, sendo o $\mathrm{pH}$ da formulação A superior $(\mathrm{p}<0,05)$ ao $\mathrm{pH}$ das demais formulações. Esta variação inicial dos valores de $\mathrm{pH}$ pode ter ocorrido devido à adição, de forma isolada ou combinada da farinha de polpa de banana verde ou inulina nas demais formulações.

No tempo de 1 hora de fermentação foi observado uma redução significativa do $\mathrm{pH}$, onde o $\mathrm{pH}$ da formulação $\mathrm{A}$ foi superior $(\mathrm{p}<0,05)$ ao $\mathrm{pH}$ das demais formulações. As formulações $\mathrm{A}, \mathrm{B}$ e $\mathrm{C}$ apresentaram valores médios de $\mathrm{pH}$ iguais a 5,67, 5,36 e 5,32, que corresponde a uma redução, em relação ao $\mathrm{pH}$ inicial, de $22,3 \%, 24,9 \%$ e $25,6 \%$, respectivamente. Após 4 horas de fermentação, os leites fermentados das formulações A, B e $\mathrm{C}$ atingiram os valores médios de $\mathrm{pH}$ iguais a 4,57, 4,73 e 4,66, respectivamente, sendo as formulações A e $\mathrm{C}$ estatisticamente iguais ( $\mathrm{p}>0,05)$. Durante o processo fermentativo, as bactérias láticas produzem metabólitos primários como o ácido lático, o qual é o principal responsável pela redução de $\mathrm{pH}$

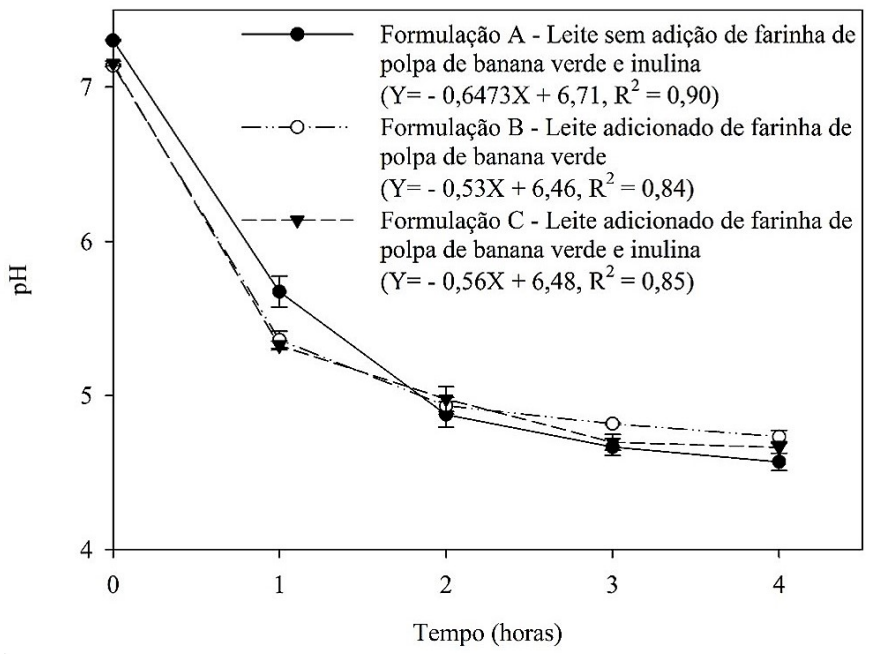

Figura 1 - Variação de pH durante a fermentação dos leites fermentados 
(MONTEIRO; GOMES, 2018). Maestri et al. (2014) observaram resultado semelhante, onde a adição de inulina nas concentrações de $1 \%$ e $2 \%$ em leite fermentado não influenciou o tempo de fermentação.

A Figura 2 mostra a variação da acidez titulável durante o processamento do leite fermentado. Os valores médios de acidez titulável inicial das formulações $\mathrm{A}, \mathrm{B}$ e $\mathrm{C}$ não apresentaram diferença significativa $(\mathrm{p}>0,05)$ e foram iguais a $0,15 \%, 0,16 \%$ e $0,14 \%$, respectivamente. No final do processo, a acidez atingiu os valores de $0,93 \%, 0,98 \%$ e $0,86 \%$ para formulações $\mathrm{A}$, $\mathrm{B}$ e $\mathrm{C}$, respectivamente, sendo as formulações A e $B$ superiores $(p<0,05)$ à formulação $C$.

Deste modo, todas as formulações apresentaram acidez adequada em relação à legislação de alimentos vigente. De acordo com a Instrução Normativa $n^{\circ} 46$, de 23 de outubro de 2007, Regulamento Técnico de Identidade e Qualidade de Leites Fermentados, o leite fermentado deve apresentar acidez titulável entre 0,6 e 2,0 g de ácido lático por $100 \mathrm{~g}$ de produto (BRASIL, 2007).

\section{Análise microbiológica}

As contagens de $S$. thermophilus dos leites fermentados das formulações $\mathrm{A}, \mathrm{B}$ e $\mathrm{C}$ não apresentaram diferença significativa $(\mathrm{p}>0,05)$ nos tempos de armazenamento de 1,14 e 28 dias e as contagens médias das formulações foram iguais a 9,04, 9,20 e 8,77 log UFC/g, respectivamente (Figura 3). As contagens do leite fermentado da formulação A apresentaram diferença significativa $(p<0,05)$ nos diferentes tempos e foi mais elevada no tempo de 14 dias, onde foi igual a $9,18 \log \mathrm{UFC} / \mathrm{g}$. Na formulação B, as contagens nos tempos 1 e 14 dias não apresentaram diferença significativa ( $\mathrm{p}>0,05)$ e foram iguais a 9,05 e $9,21 \log \mathrm{UFC} / \mathrm{g}$ respectivamente, e foram maiores em relação à contagem do tempo de 28 dias. Na formulação $\mathrm{C}$, as contagens nos diferentes tempos também apresentaram diferença $(\mathrm{p}<0,05)$ e foi maior no tempo de 14 dias, onde foi igual a 9,2 log UFC/g. A redução das contagens a partir de 14 dias pode ter ocorrido devido à redução da disponibilidade de nutrientes e ao efeito inibitório proporcionado por metabólitos

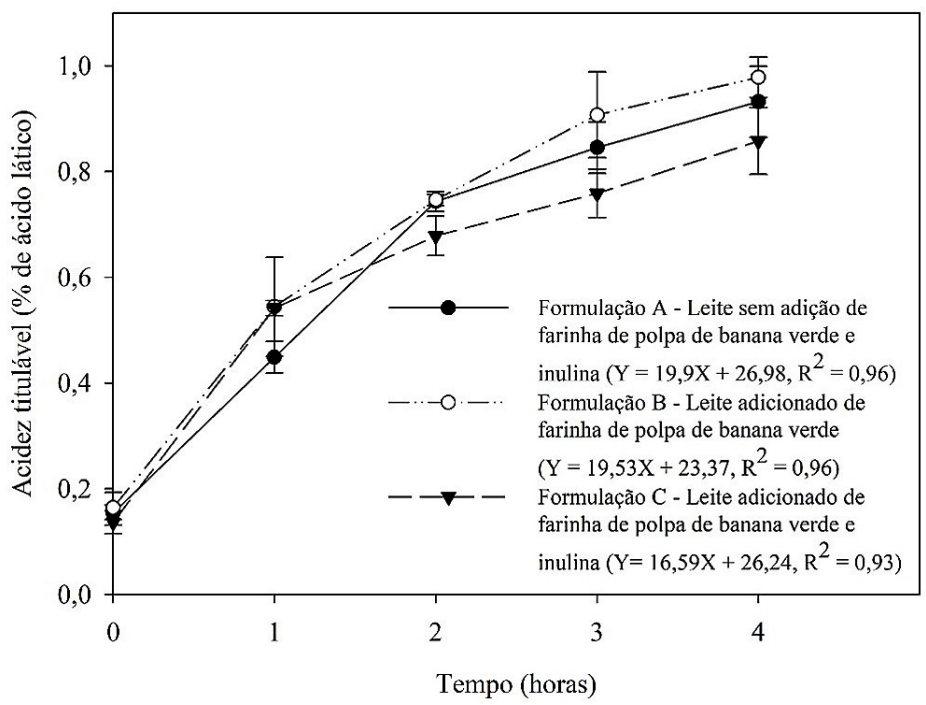

Figura 2 - Variação da acidez titulável durante a fermentação dos leites fermentados 
primários como o ácido lático. No entanto, os leites fermentados das diferentes formulações apresentaram-se dentro do padrão de qualidade exigido pela legislação durante o período de 28 dias de armazenamento.

De acordo com a Instrução Normativa $n^{\text {o } 46, \text { de }} 23$ de outubro de 2007, Regulamento Técnico de Identidade e Qualidade de Leites Fermentados, o leite fermentado obtido por meio do uso isolado ou em associação dos micro-organismos Lactobacillus acidophilus, L. casei, Bifidobacterium sp., S. salivarius subsp. thermophilus e/ou outras bactérias ácido-lácticas deve apresentar contagem mínima de $10^{6} \mathrm{UFC} / \mathrm{g}$ (BRASIL, 2007).

Assim como no presente estudo, outros autores também verificaram que prebióticos, como a inulina e a farinha de polpa de banana verde, utilizados de forma isolada ou em associação com outros prebióticos, não influenciam na sobrevivência de $S$. thermophilus. Fuchs et al. (2006) verificaram que a adição de $1 \%$ de inulina e $5 \%$ de oligofrutose em iogurte não influenciou na contagem de $S$. thermophilus, L. casei e $L$. bulgaricus durante 28 dias de armazenamento a $4^{\circ} \mathrm{C}$. De maneira semelhante, no estudo realizado por Batista et al. (2017), não foi observado efeito significativo da adição de farinha de polpa de banana verde na contagem de $S$. thermophilus nos tempos de 1, 7, 14 e 21 dias de armazenamento do produto, onde a contagem em 21 dias foi igual a $8 \log \mathrm{UFC} / \mathrm{g}$.

\section{CONCLUSÕES}

A utilização de farinha de polpa de banana verde e inulina, de forma isolada ou combinada, não influencia no processo de produção de leite fermentado inoculado com Streptococcus thermophilus e na multiplicação do micro-organismo durante o armazenamento do produto.

\section{REFERÊNCIAS}

ALKARKHI, A. F. M. et al. Comparing physicochemical properties of banana pulp

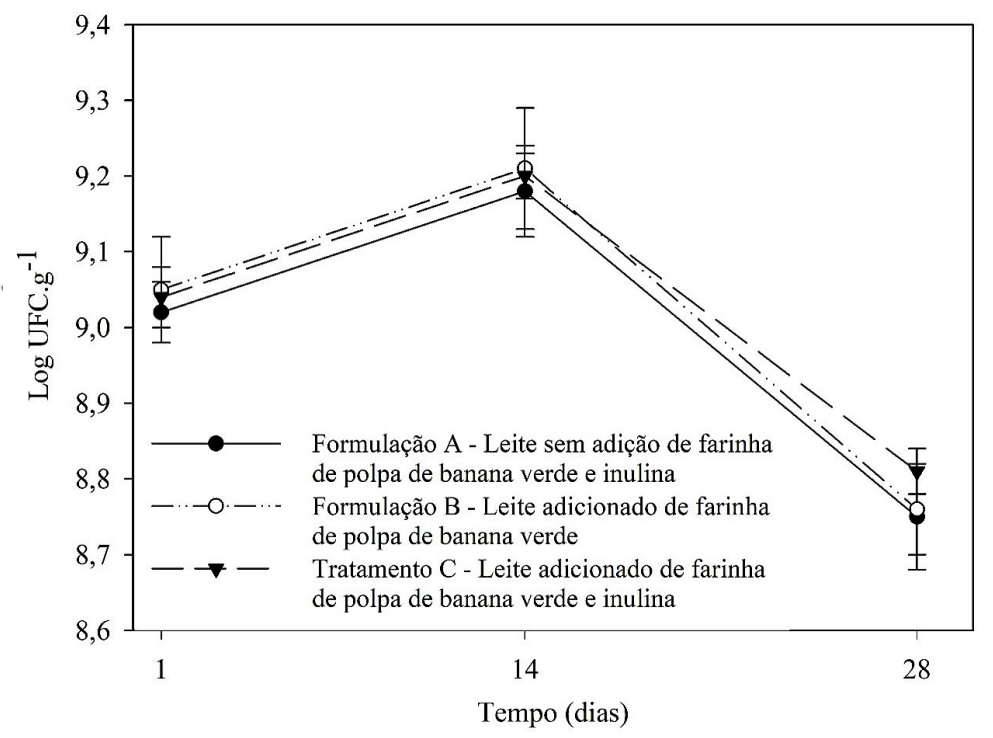

Figura 3 - Contagem de Streptococcus termophilus nos leites fermentados durante o período de 28 dias de armazenamento a $4^{\circ} \mathrm{C}$ 
and peel flours prepared from green and ripe fruits. Food Chemistry, v. 129, n. 2, p. 312-318, 2011.

ANDRADE, B. A. et al. Produção de farinha de banana verde (Musa spp.) para aplicação em pão de trigo integral. Brazilian Journal of Food Technology, v. 21, e2016055, 2018. DOI: 10.1590/1981-6723.5516, 2018.

BARAT, A; OZCAN, T. Growth of probiotic bacteria and characteristics of fermented milk containing fruit matrices. International Journal of Dairy Technology, v. 71, n. 1, p.120-129, 2018. DOI: 10.1111/14710307.12391

BARAUSKAITE, D. et al. Eating healthy to impress: How conspicuous consumption, perceived self-control motivation, and descriptive normative influence determine functional food choices. Appetite, v. 131 , p. 59-67, 2018. DOI: 10.1016/j. appet.2018.08.015

BATISTA, A. L. D. et al. Developing a symbiotic fermented milk using probiotic bacteria and organic green banana flour. Journal of Functional Foods, v. 38, p. 242-250, 2017. DOI: $10.1016 / 7.9 \mathrm{ff} .2017 .09 .037$

BORGES, A. M; PEREIRA, J; LUCENA, E. M. P. Caracterização da farinha de banana verde. Food Science and Technology, v. 29, n. 2 , p. 333-339, 2009. DOI: 10.1590/S010120612009000200015

BORTOLOZO, E. Q.; QUADROS, M. H.R. Aplicação de inulina e sucralose em iogurte.

Revista Brasileira de Tecnologia Industrial, v. 1, n. 1, p. 38-40, 2007. DOI: 10.3895/ S1981-36862007000100004

BRASIL. Ministério da Agricultura, Pecuária e Abastecimento. Instrução Normativa $n^{\circ}$
46, de 23 de outubro de 2007. Regulamento técnico de produção, identidade e qualidade de leites fermentados. Diário Oficial da União: seção 1, Brasília, DF, n. 205, p. 4, 24 out. 2007.

BRASIL. Ministério da Saúde. Agência Nacional de Vigilância Sanitária. Portaria

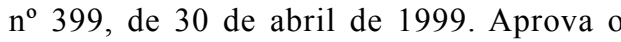
Regulamento de procedimentos para registro de alimento com alegação de propriedades funcionais e ou de saúde em sua rotulagem. Diário Oficial da União: seção 1, Brasília, DF, n. 82-E, p. 12, 3 maio. 1999.

BRASIL. Ministério da Saúde. Agência Nacional de Vigilância Sanitária. Resolução RDC n 263, de 22 de setembro de 2005. Aprova o Regulamento Técnico para produtos de cereais, amidos, farinhas e farelos. Diário Oficial da União: seção 1, Brasília, DF, n. 184 , p. 368,23 set. 2005 .

CAMPUZANO, A.; ROSELL, C. M.; COMEJO, F. Physicochemical and nutritional characteristics of banana flour during ripening. Food Chemistry, v. 256, p. 11-17, 2018. DOI: 10.1016/.foodchem.2018.02.113

DENARDIN, C. C.; SILVA, L. P. Estrutura dos grânulos de amido e sua relação com propriedades físico-químicas. Ciência Rural, v. 39, n. 3, p. 945-954, 2009. DOI: 10.1590/80103-84782009005000003

FIORDA, F. A. et al. Farinha de bagaço de mandioca: Aproveitamento de subproduto e comparação com fécula de mandioca. Pesquisa Agropecuária Tropical, v. 43, n. 4, p. 408-416, 2013. DOI: 10.1590/8198340632013000400005

FUCHS, R. H. B. et al. Utilização de Lactobacillus casei e cultura iniciadora na obtenção de iogurte suplementado com 
inulina e oligofrutose. Boletim do Centro de Pesquisa e Processamento de Alimentos, v. 24 , n. 1 , p. $83-98,2006$. DOI: $10.5380 / \mathrm{cep}$. v2411.5293

LATIMER Jr., G. W. (ed.). Official methods of analysis of AOAC International. 19th ed. Gaithersburg: AOAC International, 2012.

MAESTRI, B. et al. Avaliação do impacto da adição de inulina e de maçã em leite fermentado probiótico concentrado. Brazilian Journal of Food Technology, v. 17 , n. 1 , p. 58-66, 2014. DOI: $10.1590 /$ bjft.2014.009

MATTILA-SANDHOLM, T. et $a l$. Technological challenges for future probiotic foods. International Journal of Dairy Technology, v. 12, n. 2/3, p. 173-182, 2002. DOI: $10.1016 / 80958-6946(01) 00099-1$

MATOS, M. et al. Análise sensorial e nutricional de Brownie com farinha de banana verde. Revista Brasileira de Obesidade, Nutrição e Emagrecimento, v. 11. n. 68. p. 722-730, 2017. Supl. 2.

MONTEIRO, P. S.; GOMES, P. M. S. Production of kefir as alternative for utilization of buttermilk. Revista do Instituto de Laticínio Cândido Tostes, v. 73, n. 3, p. 162-171, 2018. DOI: 0.14295/2238-6416. v7313.691

MORRIS, P. C.; BRYCE, J. H. (ed.). Cereal Biotechnology. 1. ed. Boca Raton: CRC Press, 2000. 264 p.

NETO, J. M. et al. Componentes químicos da farinha de banana (Musa sp.) obtida por meio de secagem natural. Revista Brasileira de Engenharia Agrícola e Ambiental, v. 2, n. 3, p. 316-318, 1998. DOI: 10.1590/1807-1929/ agriambi.v2n3p316-318
OLIVEIRA et al. Avaliação da qualidade de pão com adição de farinha e purê da banana verde. Revista Brasileira de Fruticultura, v. 37, n. 3, p. 699-707, 2015. DOI: $10.1590 / 0100-2945-176 / 14$

RAIZEL, R. et al. Efeitos do consumo de probióticos, prebióticos e simbióticos para o organismo humano. Revista Ciência \& Saúde, v. 4, n. 2, p. 69-70, 2011. DOI: 10.15448/1983-652X.2011.2.8352

SAAD, S. M. I. Probióticos e prebióticos: O estado da arte. Revista Brasileira de Ciências Farmacêuticas, v. 42, n. 1, 2006. DOI: $10.1590 / 81516-93322006000100002$

SANTOS, T. J. et al. Microbial, physical, chemical and sensory properties of Minas Frescal cheese with inulin and gum acacia. Acta Scientiarum Technology, v. 37, n. 1, p. 155-160,2015. DOI: 10.4025/ actascitechnol.v37i1.19744

SHOAIB, M. et al. Inulin: Properties, health benefits and food applications. Carbohydrate Polymers, v. 147, p. 444-454, 2016. DOI: 10.1016/.carbpol.2016.04.020

SILVA, M. E. V. et al. Desenvolvimento de iogurte funcional adicionado de pasta de banana verde. Higiene Alimentar, v. 31, n. $266 / 267$, p. $490-494,2017$ a.

SILVA, $\mathrm{N}$ et al. Manual de Métodos de Análise Microbiológica de Alimentos e Água. 5. ed. São Paulo: Blucher, 2017b. $535 \mathrm{p}$.

SILVA, N. B. et al. Ação antimicrobiana da farinha de banana verde sobre microrganismos presentes no biofilme dentário. Revista e-ciência, v. 4, n. 2, p. 26-31, 2016. DOI: 10.19095/rec.v4i2.170.g79 
TAMIME, A. Y; ROBINSON, R. K. Yogur, Ciencia y Tecnologia. Zaragoza: Acribia, 1990.

TORRES, L. L. G. et al. Efeito da umidade e da temperatura no processamento de farinha de banana verde (Musa acuminata, grupo AAA) por extrusão termoplástica. Boletim da Sociedade Brasileira de Ciência e Tecnologia de Alimentos, v. 23, n. 2, p. 273-290, 2005. DOI: $10.5380 /$ cep.v23i2.4488

VALDEZ et al. Estabilidad y textura de reestructurados de came de cabra adicionados con inulina gelificados en frio. Interciencia: Revista de Ciencia y Tecnologia de América, v. 40, n. 8, p. 576-580, 2015.

WALISZEWSKI, K. N. et al. Changes of banana starch by chemical and physical modification. Carbohydrate Polymers, v. 52, n. 3, p. 237-242, 2003. DOI: 10.1016/8S0144-8617(02)00270-9

ZENEBON, O.; PASCUET, N. S.; TIGLEA, P. (coord.). Métodos Físico-Químicos para Análise de Alimentos. 4. ed., 1. ed. digital. São Paulo: Instituto Adolfo Lutz, 2008.1020 p. 